\title{
Difficult Infected Wound After Colorectal Surgery
}

\author{
Prem Rathore \\ The Townsville Hospital, James Cook University, Queensland \\ Australia
}

\section{Introduction}

Surgical site infection (SSI) is a well known and commonly encountered scenario following major colorectal resection and has been documented as being a potentially morbid and costly complication.

Surgical wounds in normal, healthy individuals heal through an orderly sequence of physiologic events that include inflammation, epithelialisation, fibroplasia, and maturation. Mechanical failure or failure of wound healing at the surgical site can lead to disruption of the closure leading to seroma, hematoma, wound dehiscence or hernia. Other complications include surgical site infection and nerve injury.

For this reason, of late, emphasis has been placed on more efficient management of these patients including early recognition, and prompt treatment with a view to improve patient outcomes which are measured both in terms of postoperative morbidity, prolonged hospital stay and by extension an increased demand on finite hospital resources ${ }^{1}$.

However, there has been wide discrepancy in the reported incidence of incisional SSI following colorectal surgery, ranging from 3 to $30 \%$ (1). Additionally, there has been no clear consensus on the risk factors contributing to SSI following colorectal surgery, which has limited the data's value to surgeons involved in quality improvement programs hoping to address specific variables that could reduce this risk.

In this era of managed care organizations where patients expect short hospital stay and onestage resections are becoming more frequent, peri operative assessment of risk factors for wound infection should be intensified for the patient.

Surgical site infections (SSI) are the third most common hospital-acquired infection and account for $14 \%$ to $16 \%$ of all such infections. However, in surgical patients, SSI is the leading cause of hospital-acquired infection ${ }^{2,3}$. Similar incidence of SSI has been documented by various studies in patients after colorectal surgery.

The National Nosocomial Infection Surveillance system surveys all colorectal surgeries together, without differentiating the type of colorectal surgery performed. The outcome of their survey showed rectal surgery may have a higher risk for SSI, and identifying risk factors that are more specific to this procedure would be a better indicator to predict the possibility of SSI. 
Several reports have described the substantial cost of these infections in terms of attributable mortality, 3 increased morbidity measured as increased postoperative hospital length of stay, and increased hospital costs.

\section{Risk factors}

Various studies have identified multiple risk factors and other associations which have a direct bearing on the incidence of these infections.

a. Type of surgery: Timing of the surgical procedure does not significantly predispose or preclude wound infections as it occurs in patients who have undergone both emergency surgery as well as those that had an elective procedure.

b. Patient related risk factors for surgical site infection ${ }^{4}$ (Table 1): This group of risk factors have a significant impact on the incidence of surgical site infection. Included in this group are pre-existing conditions like diabetes and cardiovascular disease. Patients nutritional status - both malnutrition and obesity and life style habits like smoking can cause significant impact on post-operative wound. Prior medical history of surgery, irradiation or cancer also adversely effect wound healing.

\begin{tabular}{|ll|}
\hline 1. & Diabetes \\
2. & Obesity \\
3. & Immunosuppression \\
4. & Cardiovascular disease \\
5. & Smoking \\
6. & Cancer \\
7. & Previous surgery \\
8. & Malnutrition and \\
9. & Prior irradiation \\
\hline
\end{tabular}

Table 1. Patient Related Risk Factors for Surgical Site Infection 4

c. Technique related risk factors for surgical site infection ${ }^{4}$ (Table 2): Various surgical related factors affect wound healing differently. This includes both pre surgical patient preparation and post operative care. Intra operative procedures including the surgical techniques like excessive use of electrocautery, poor haemostasis and tissue trauma can adversely affect wound healing as can the length of the surgery. Insertion and duration of intra abdominal drains remains a controversial point.

1. Use of electrocautery

2. Closure of subcutaneous tissue

3. Duration of surgical scrub

4. Skin antisepsis

5. Preoperative shaving

6. Preoperative skin prep

7. Duration of operation

8. Antimicrobial prophylaxis
9. Operating room ventilation

10. Inadequate sterilisation of instruments

11. Foreign material in the surgical site

12. Surgical drains

13. Poor haemostasis

14. Failure to obliterate dead space

15. Tissue trauma

Table 2. Technique Related Risk Factors For Surgical Site Infection 4 
d. Factors associated with increased risk of fascial disruption ${ }^{5}$ (Table 3): Multiple factors can increase the changes of loss of integrity of the fascia and largely relate to patient factors including patients' premorbid and associated medical conditions as does patient demographics.

1. Age $>65$ years

2. Emergency surgery

3. Anemia: hemotocrit $<30$ percent

4. Obesity: body mass index $>30 \mathrm{~kg} / \mathrm{m}^{2}$

5. Ascites

6. Diabetes mellitus

7. Pulmonary disease, COPD, chronic cough
8. Shock

9. Poor nutrition: albumin $<3.5 \mathrm{~g} / \mathrm{dL}$

10. Infection

11. Immunosuppressive therapy, glucocorticoids, antineoplastic agents

12. Jaundice

13. Male gender

Table 3. Factors associated with increased risk of fascial disruption

\section{Classification of abdominal wound infection}

Surgical wound infection can be classified into different types based on various criteria6.

a. Based on the depth and the site of the surgical wound infection, the three types are:

1. Superficial incisional surgical site infection: Involves skin and subcutaneous fat (Image 1).

2. Deep incisional surgical site infection: Involves rectus sheath and preperitoneal space (Image 2).

3. Organ / space surgical site infection: Involves intraperitoneal compartment and intra abdominal organs (Image 3).

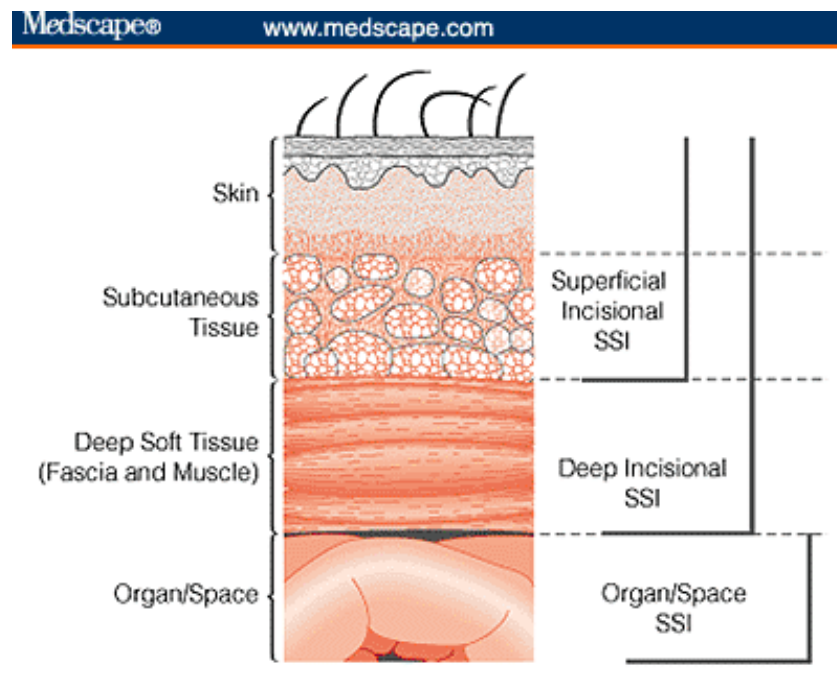

Fig. 1. 
b. Based on the type of wound they are classified as:

1. Clean

2. Clean contaminated

3. Contaminated

4. Dirty

Studies have shown an association between the type of wound and the incidence of surgical site infection (Table 4):

\begin{tabular}{|l|l|l|}
\hline Classification & Examples & Incidence of SSI (\%) \\
\hline Clean & $\begin{array}{l}\text { Elective surgery without violation of the gut or } \\
\text { infected spaces }\end{array}$ & $<2$ \\
\hline $\begin{array}{l}\text { Clean } \\
\text { contaminated }\end{array}$ & $\begin{array}{l}\text { Elective bowel surgery (prepared bowel, } \\
\text { mechanical and antibiotic) }\end{array}$ & $5-15$ \\
\hline Contaminated & $\begin{array}{l}\text { Emergent bowel surgery (unprepared bowel, } \\
\text { minor spillage), drainage of infected spaces }\end{array}$ & $15-30$ \\
\hline Dirty & $\begin{array}{l}\text { Grossly contaminated traumatic wounds, } \\
\text { significant intestinal spillage, grossly infected } \\
\text { and devitalized tissue (necrotizing infection) }\end{array}$ & $>30$ \\
\hline
\end{tabular}

Table 4. Wound Classification and Risk for Surgical Site Infection

\section{Clinical manifestation and diagnosis}

As with infection anywhere, surgical site infections present with localized erythema, induration, warmth, and pain at the incision site. Purulent wound drainage and separation of the wound may occur.

Some patients will have systemic evidence of their infection such as fever and leukocytosis.

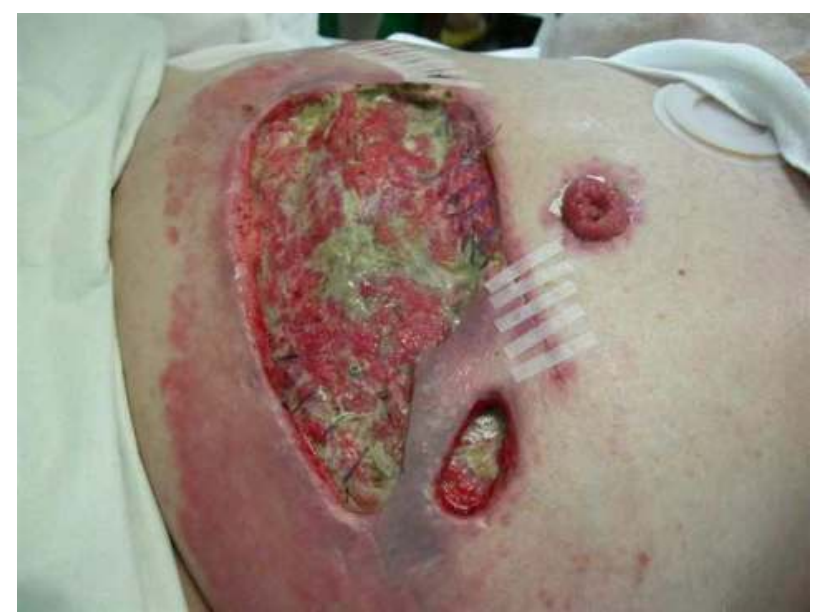

Image 1. Superficial incisional surgical site infection showing skin and subcutaneous fat involvement. 


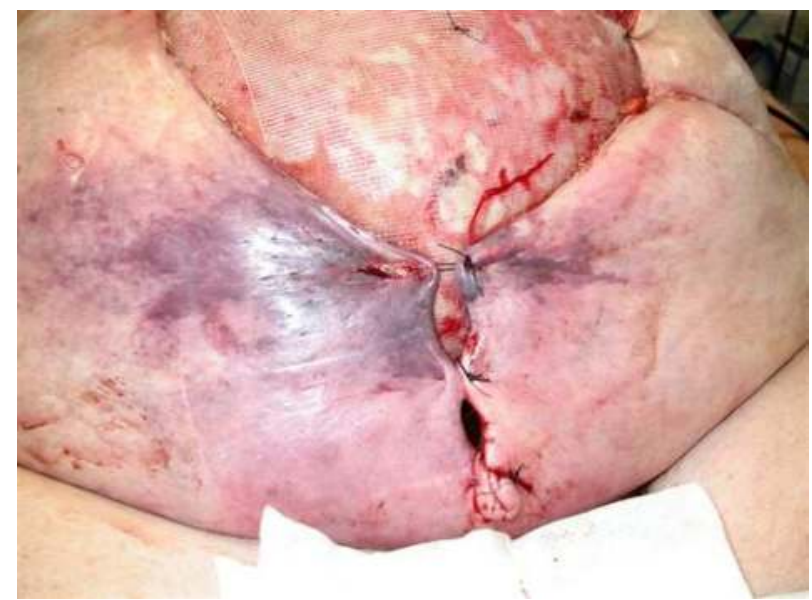

Image 2. Deep incisional surgical site infection involving rectus sheath and preperitoneal space.

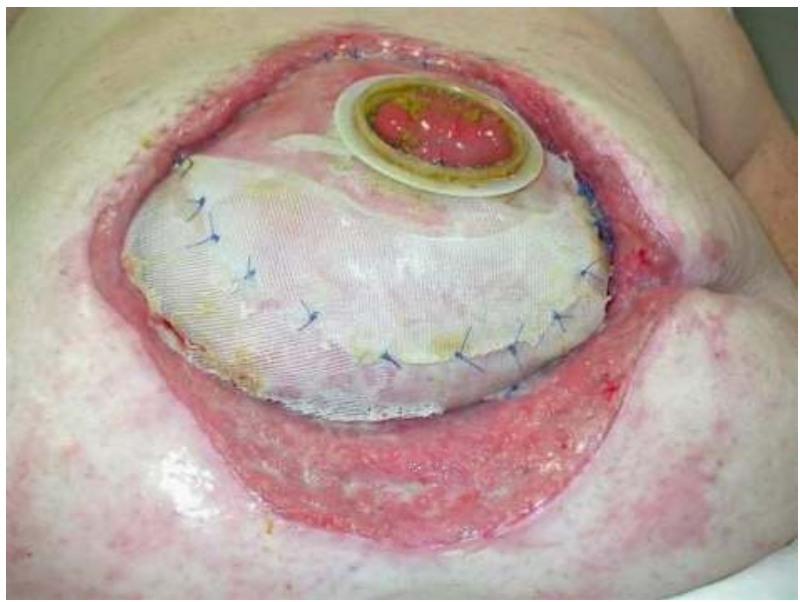

Image 3. Organ surgical site infection shown as an open abdomen with Involvement of the peritoneal cavity and omentum managed by mesh placement.

Diagnosis of surgical site infection is largely clinical.

Role of imaging is limited to those patients in whom there is a clinical suspicion of deep space infections or collections. Of the imaging modalities, Computed Tomography is the preferred modality for assessment.

Ultrasound may have a limited role in assessing deep space infections but can evaluate collections related to superficial wounds, particularly, if the clinical evaluation is difficult or inconclusive. 


\section{Complication of SSI}

In addition to the complications related directly to the wound, patients with SSI can have other complications based on their pre surgical risk factors and co morbidities that can adversely affect their long term outcome and prolong their convalescence.

These complications have been well documented and researched and include long hospital stay, increasing morbidity, SIRS - Sepsis - MOF and even death.

\subsection{Management}

Recent studies have shown the strong influence of the various risk factors that results in an increase in the incidence of surgical site infection. Thus, there has been a shift in the approach to the management of these patients with emphasis being placed on prophylaxis.

\subsubsection{Prophylaxis}

- Adequately identifying and correcting the various systemic co-morbidities thus optimising the pre-operative status and reducing the pre-operative risk for SSI.

- This has shown to be as important as post-operative and intra-operative care. It includes ensuring adequate control of diabetes and assessment and correction of cardiovascular problems pre-operatively.

- $\quad$ Studies have shown that cessation of smoking at least a week prior to surgery reduces the risk of SSI.

- Both reduction of weight in obese patients and improvement of nutrition in cachectic patients have shown to favourably improve surgical outcome.

- Optimising surgical techniques at various levels starting with adequate patient preparation for surgery which include antibacterial shower on the day of surgery, shaving of the site on table.

- Adequate antimicrobial prophylaxis which is continued intra operatively at 4 hourly intervals.

- Mass closure of the abdominal wound incorporating all layers of the rectus sheath taking wide tissue bites of more than $1 \mathrm{~cm}$ and with short stitch interval (less than $1 \mathrm{~cm}$ ) using suture length to wound length ratio of 4 to 1 .

- Reducing tissue trauma during surgery by gentle dissection of tissue, cautious use of electrocautery and saline wash-out of the wound has shown a lower incidence of SSI. Reducing operative time and appropriate use of intrabdominal drains also reduces the risk.

- $\quad$ Best practices for preventing surgical site infections ${ }^{7}$ :

Evidence category IA - Well designed studies

1. Cancel elective surgery if the patient has an infection at or remote from the surgical site

2. Achieve maximal subcutaneous concentration of peri operative antibiotics

3. Maintain prophylactic antibiotics for only a few hours after closing incisions

4. If it is necessary to remove hair, use clippers, not shaving, immediately before operation

Evidence category IB - Good evidence and expert consensus

1. Control glucose levels in diabetic patients and avoid peri operative hyperglycemia 
2. Encourage patients who use tobacco products to quit using or to abstain for 30 days prior to surgery

3. Have the patient shower or bathe with an antiseptic agent on at least the night before surgery

4. Follow strict standards for sterilizing instruments, disinfecting operating room, and air circulation

5. Do not routinely use vancomycin for prophylaxis if other agents are appropriate

6. Do not use UV radiation in the operating room for infection prophylaxis

7. Surgical staff who have draining skin lesions are excluded from duty

8. Surgical staff should wear sterile clothing and gloves

9. Surgical team hand hygiene to include keeping fingernails short, scrubbing with antiseptic to elbows for 2-5 min, using sterile towels

10. Use appropriate topical microbicides during surgery

11. Use proper surgical technique

12. Apply sterile dressing to incision for $24-48$ hours postoperatively and wash hands before contact with surgical site

13. Perform hospital surveillance for surgical site infection

\subsubsection{Definitive management}

Definitive management of SSI depends on the type of infection.

\subsubsection{Superficial incisional surgical site infection}

Infected wounds are opened, explored, drained, irrigated, débrided and dressed open.

If fascial disruption is suspected, drainage should be performed in the operating room.

The severity of the infection determines the need for antibiotic therapy. Once the infection has cleared and granulation tissue is apparent, the wound can be closed secondarily.

\subsubsection{Deep incisional surgical site infection}

\section{Fascial dehiscence:}

Fascial disruption is due to abdominal wall tension overcoming tissue or suture strength, or knot security as a result of infection or collection. It can occur either early or late in the postoperative period and can involve a portion of the incision (i.e, partial dehiscence) or the entire incision (i.e, complete fascial dehiscence).

The incidence of fascial disruption ranges from 0.4 to $3.5 \%$ depending upon the type of surgery performed. Despite improved perioperative care and stronger suture materials, the incidence and morbidity of fascial dehiscence is largely unchanged.

When fascial disruption is suspected, wound exploration should be performed in the operating room. Complete fascial dehiscence is associated with a mortality rate of $10 \%$ and is a surgical emergency. At the bedside, a moist dressing is placed over the wound and a binder placed around the patient's abdomen to prevent evisceration on the way to the operating room.

Once opened, the wound is thoroughly debrided. Treatment options include either using VAC dressing or mass closure. Mass closure done with continuous or retention non- 
absorbable sutures is an option only if the intra-abdominal pressure and tissue oedema intraoperatively is not high. In such cases VAC dressing is the preferred treatment.

\section{Prevention}

Meta-analyses related to abdominal fascial closure suggest an optimal technique for closure of abdominal surgical wounds includes $(8,9)$ :

- Use of a simple running technique

- Use of \#1 or \#2 delayed absorbable monofilament suture

- Use of mass closure to incorporate all layers of the abdominal wall (except skin)

- $\quad$ Taking wide tissue bites $(\geq 1 \mathrm{~cm})$

- Use of a short stitch interval $(\leq 1 \mathrm{~cm})$

- Use of a suture length to wound length ratio of 4 to 1

- Use of non-strangulating tension on the suture.

\subsubsection{Organ/Space surgical site infection}

One of the critical decisions in the surgical treatment of patients with severe peritonitis is whether to use an open-abdomen or a closed-abdomen technique.

\section{Closed abdomen technique}

The goal of the closed-abdomen technique is to provide definitive surgical treatment at the initial operation which saves the patient from repetitive trauma of anaesthesia and surgery.

Opting for this technique should be judicious in an unstable patient.

\section{Open abdomen technique}

VAC dressing and temporary closure with sponge or mesh are types of open abdomen techniques which are valuable tools for the management of patients with acidosis, hypothermia and coagulopathy. This is a very resource-intensive decision.

The goal of the open-abdomen technique is to provide easy, direct access to the affected area. Source control is achieved through repeated reoperations or through open packing of the abdomen. This technique may be well suited for initial damage control in extensive peritonitis.

The open-abdomen technique should also be considered in patients who are at high risk for the development of abdominal compartment syndrome (eg, patients with intestinal distension, extensive abdominal wall and intra-abdominal organ edema), because attempts to perform primary fascial closure under significant tension in these circumstances are associated with an increased incidence of multiple organ failure (eg, renal, respiratory), necrotizing abdominal wall infections, anastomotic leak, entero-cutaneous fistula and mortality.

Temporary closure of the abdomen to prevent herniation and contamination can be achieved by using various materials (Table 5):

1. Self-adhesive impermeable membrane dressings using sponge and opsite. Though it is in inexpensive and easy to apply, the major disadvantage is difficulty in maintaining wound seal. In addition, there is loss of large volumes of extracellular fluid.

2. Mesh like Vicryl and Dexon made of absorbable material can be directly applied over bowel, but the drawbacks are loss of strength in the presence of infection and higher incidence of ventral hernia development. 


\begin{tabular}{|c|c|c|c|}
\hline $\begin{array}{l}\text { Closure } \\
\text { Technique }\end{array}$ & Description & Advantages & Disadvantages \\
\hline $\begin{array}{l}\text { Self-adhesive } \\
\text { impermeable } \\
\text { membranes }\end{array}$ & $\begin{array}{l}\text { Abdominal dressing with } \\
\text { gauze and coverage of the } \\
\text { entire wound with } \\
\text { impermeable membrane with } \\
\text { and without placement of } \\
\text { drains between the layers }\end{array}$ & $\begin{array}{l}\text { Inexpensive } \\
\text { Easy application }\end{array}$ & $\begin{array}{l}\text { Difficult to maintain seal } \\
\text { Potentially large volume losses } \\
\text { Fistula formation }\end{array}$ \\
\hline $\begin{array}{l}\text { Vicryl or } \\
\text { Dexon mesh }\end{array}$ & $\begin{array}{l}\text { Suturing of the mesh to the } \\
\text { fascial edges; different options } \\
\text { for dressing }\end{array}$ & $\begin{array}{l}\text { Can be applied directly } \\
\text { over bowel } \\
\text { Allows for drainage of } \\
\text { peritoneal fluid }\end{array}$ & $\begin{array}{l}\text { Rapid loss of tensile strength (in } \\
\text { the setting of infection) } \\
\text { Potentially large volume losses } \\
\text { Higher incidence of later ventral } \\
\text { hernia development } \\
\text { No reopen-and-close option } \\
\text { Fistula formation }\end{array}$ \\
\hline $\begin{array}{l}\text { Polypropylene } \\
\text { mesh }\end{array}$ & $\begin{array}{l}\text { Suturing of the mesh to the } \\
\text { fascial edges; different options } \\
\text { for dressing }\end{array}$ & $\begin{array}{l}\text { Good tensile strength } \\
\text { Allows for drainage of } \\
\text { peritoneal fluid }\end{array}$ & $\begin{array}{l}\text { Risk of intestinal erosion when } \\
\text { applied directly over bowel } \\
\text { Potentially large volume losses } \\
\text { High risk of mesh infection } \\
\text { Fistula formation }\end{array}$ \\
\hline $\begin{array}{l}\text { GORE-TEX } \\
\text { mesh }\end{array}$ & $\begin{array}{l}\text { Suturing of the mesh to the } \\
\text { fascial edges; different options } \\
\text { for dressing }\end{array}$ & $\begin{array}{l}\text { Good tensile strength } \\
\text { Reopen and close } \\
\text { option }\end{array}$ & $\begin{array}{l}\text { Potential fluid accumulation } \\
\text { underneath the mesh } \\
\text { Limited tissue integration and } \\
\text { granulation tissue formation } \\
\text { over the mesh } \\
\text { Risk of mesh infection } \\
\text { Fistula formation }\end{array}$ \\
\hline $\begin{array}{l}\text { Human } \\
\text { acellular } \\
\text { dermis }\end{array}$ & $\begin{array}{l}\text { Suturing of the mesh to the } \\
\text { fascial edges }\end{array}$ & Good tensile strength & $\begin{array}{l}\text { Expensive } \\
\text { Needs } 10 \text { minutes of } \\
\text { rehydration }\end{array}$ \\
\hline $\begin{array}{l}\text { Vacuum- } \\
\text { assisted } \\
\text { closure device }\end{array}$ & $\begin{array}{l}\text { Sponges applied over mesh } \\
\text { and attached to controlled, } \\
\text { low-level suction }\end{array}$ & $\begin{array}{l}\text { Controlled drainage of } \\
\text { secretions } \\
\text { Accelerated granulation } \\
\text { tissue formation } \\
\text { Wound debridement } \\
\text { Can remain in place for } \\
\text { longer than } 48 \text { hours }\end{array}$ & $\begin{array}{l}\text { Cost } \\
\text { Risk of intestinal erosion when } \\
\text { applied directly over bowel } \\
\text { Fistula formation }\end{array}$ \\
\hline $\begin{array}{l}\text { Wittmann } \\
\text { patch }\end{array}$ & $\begin{array}{l}\text { Suturing of artificial burr (ie, } \\
\text { Velcro) to fascia, staged } \\
\text { abdom-inal closure by } \\
\text { application of controlled } \\
\text { tension }\end{array}$ & $\begin{array}{l}\text { Good tensile strength } \\
\text { Allows for easy re } \\
\text { exploration and } \\
\text { eventual primary fascial } \\
\text { closure }\end{array}$ & Fistula formation \\
\hline
\end{tabular}

Table 5. Temporary closure materials.

3. Non absorbable mesh like GORE-TEX and polypropylene can be used for closure with or without zipper. These materials have good tensile strength and provide additional option of repeated surgeries. The disadvantage, however, is mesh erosion into the bowel wall forming fistula and subsequent high risk of mesh infection. 
4. Vacuum assisted closure device has the advantage of controlled drainage of secretions. It can also be left in situ for more than 48 hours which is adequate time for the patient to recover from systemic conditions like coagulopathy or metabolic acidosis (Damage control surgery). Increased cost is a major limiting factor against widespread use.

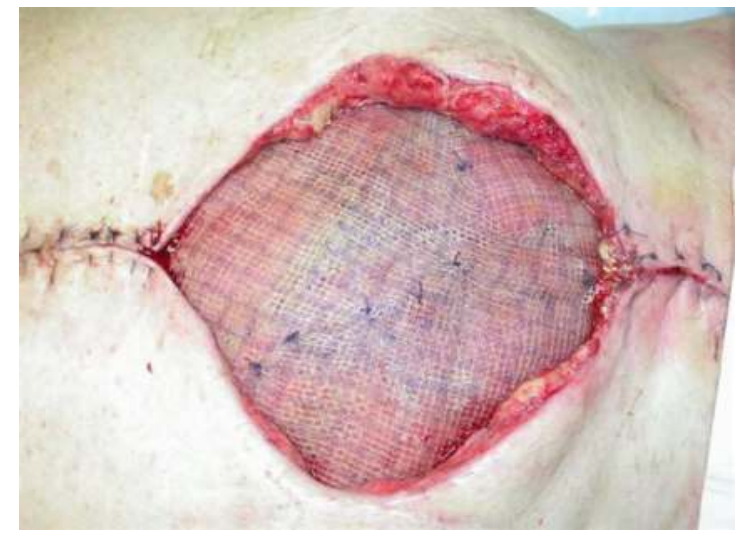

Image 4. Open abdomen technique (mesh)

\section{Emerging new techniques for management of open abdomen}

\subsection{Abdominal vacuum-assisted closure (V.A.C.) systems ${ }^{(10,11)}$}

The V.A.C. ${ }^{\circledR}$ Abdominal Dressing System is a specialty dressing indicated for temporary bridging of the open abdomen where primary closure is not possible and/or repeat abdominal entries are necessary.

The V.A.C. Abdominal Dressing System can be used to assist in the management of an open abdomen due to Abdominal Compartment Syndrome, trauma requiring damage control or staged abdominal repair, and other complex abdominal pathologies.

V.A.C systems are intended to create an environment that promotes wound healing by secondary or delayed primary intention by preparing the wound for closure, reducing edema, promoting granulation tissue formation and perfusion and by removing exudative and infectious material.

These systems are indicated for patients with open abdomen and dehisced wounds, partialthickness burns, chromic ulcers (such as diabetic, pressure or venous insufficiency).

The V.A.C. GranuFoam ${ }^{\mathrm{TM}}$ Silver Dressing is an effective barrier to bacterial penetration and may help reduce infection in the above wound types.

Placement of V.A.C systems directly in contact with exposed blood vessels, anastomotic sites, organs, or nerves is contraindicated. V.A.C. Therapy is also contraindicated for patients with malignancy in the wound, untreated osteomyelitis, non-enteric and unexplored fistulas and necrotic tissue with eschar present.

However, after debridement of necrotic tissue and complete removal of eschar, V.A.C. Therapy may be used. 
Following initiation of V.A.C Therapy, the wound can be re evaluated after 72 hours. This can either be done at the bed-side under sedation or under anaesthesia in the theatre. If the wound continues to be infected or dirty, the V.A.C system is reapplied. On the other hand, if the wound is clean, then the decision to proceed to secondary closure of the abdomen can be made.

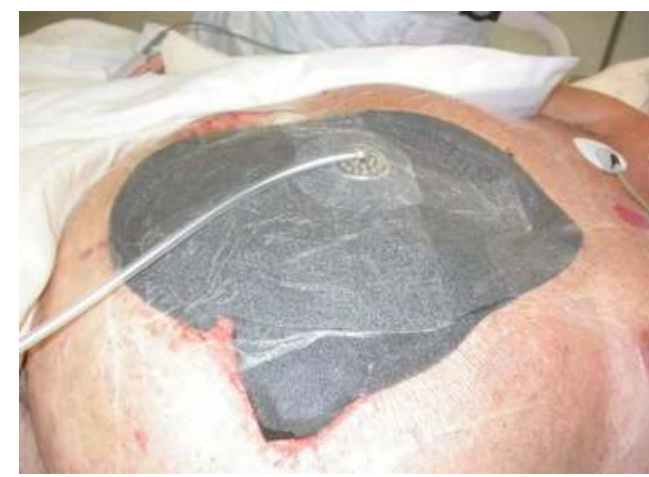

(a)

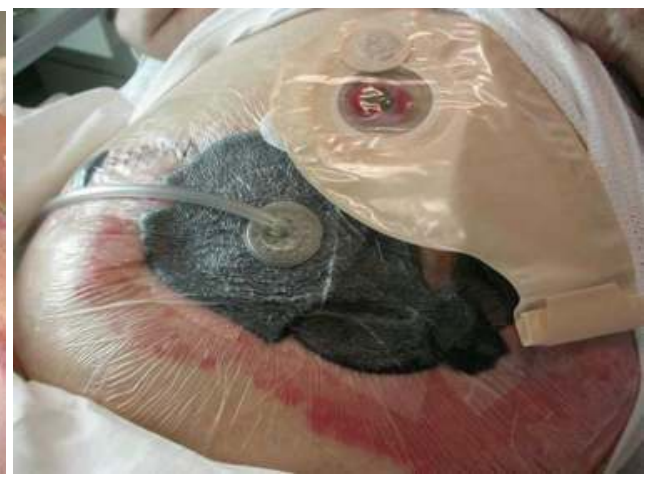

(b)

Image 5. a,b: V.A.C Therapy for open abdomen

\subsection{Mist therapy ${ }^{(12)}$}

MIST Therapy ${ }^{\circledR}$ is a painless, noncontact, low frequency ultrasound delivered through a saline mist to the wound bed.These gentle sound waves stimulate the cells within and below the wound bed to promote healing.

The result of these gentle sound waves pushing against the tissue include:

- Cell stimulation

- Reduced inflammation

- $\quad$ Reduced bacteria and bio burden

- Increased blood flow

\section{Summary}

Surgical site infection (SSI) is a well known and commonly encountered scenario following major colorectal resection and has been documented as being a potentially morbid and costly complication.

Risk factors for surgical site infection include: smoking, diabetes, malnutrition, cancer, obesity, immunosuppression, cardiovascular disease and prior incision or irradiation at the surgical site. Meticulous surgical technique that avoids excessive tissue injury and ischemia while providing adequate hemostasis are important for preventing infection.

Surgeons can modify rates of infection with preventive measures that include antibiotic prophylaxis, proper skin preparation and maintenance of sterile conditions intra operatively. Proper surgical technique with gentle tissue handling and a secure closure that does not cause tissue ischemia are also important. 
Infected wounds are opened, explored, drained, irrigated, débrided and dressed open. If fascial disruption is suspected, drainage should be performed in the operating room. The severity of the infection determines the need for antibiotic therapy. Once the infection has cleared and granulation tissue is apparent, the wound can be closed secondarily.

Fascial disruption is due to abdominal wall tension overcoming tissue or suture strength, or knot security. It can occur early or late in the postoperative period. With early fascial dehiscence, the skin closure may be intact depending upon the method of closure (ie, staples, sutures); the patient, nevertheless, is at risk for evisceration. Early postoperative fascial dehiscence is a surgical emergency. The late complication of fascial disruption is incisional hernia which can lead to bowel obstruction, ischemia and even death.

Management of the deep incisional surgical site and organ/space surgical site infection includes open abdomen technique using various types of dressings and mesh. Occasionally, single stage closure of the abdomen is used.

Of late, V.A.C dressings are the preferred choice for open abdomen management. However, the most recent development is the MIST therapy using low frequency ultrasound.

\section{References}

[1] Robert L. Smith, MD, Jamie K. Bohl, MD, Shannon T. McElearney, MD, Charles M. Friel, MD, Margaret M. Barclay, RN, ACNP-C, Robert G. Sawyer, MD, and Eugene F. Foley, MD :Wound Infection After Elective Colorectal Resection. Annals of Surgery v.239(5);May 2004.

[2] Coppa GF, Eng K, Gouge TH, et al. Parenteral and oral antibiotics in elective colon and rectal surgery. A prospective, randomized trial. Am J Surg. 1983;145:62- 65.

[3] Tang R, Chen HH, Wang YL, et al. Risk factors for surgical site infection after elective resection of the colon and rectum: a single-center prospective study of 2,809 consecutive patients. Annals of Surgery 2001;234:181-9.

[4] SHEA, APIC, CDC, SIS. Consensus paper on the surveillance of surgical wound infections. Infect Control Hosp Epidemiol 1992; 13:599.

[5] Cruse PJ. Surgical wound infection. In: Infectious Diseases, Wonsiewicz MJ (Ed), WB Saunders Co, Philadelphia 1992. p.7583:599.

[6] Mangram AJ, Horan TC, Pearson ML, etal. Guideline for prevention of surgical site infection. In: Infection Control and Hospital Epidemiology, CDC 1999; 20:24

[7] Adapted from the Centers for Disease Control Guidelines for Prevention of Surgical Site Infection (www.cdc.gov/ncidod/dhqp/gl_surgicalsite.html).

[8] Ceydeli A, Rucinski J, Wise L. Finding the best abdominal closure: an evidence-based review of the literature. Curr Surg 2005; 62:220

[9] Finding the best abdominal closure: an evidence-based review of the literature.AU Ceydeli A, Rucinski J, Wise LSO, Curr Surg. 2005;62(2):220.

[10] Vacuum-Assisted Closure of Postoperative Abdominal Wounds: A Prospective Study. Sriram Subramonia, Sarah Pankhurst, Brian J. Rowlands and Dileep N. Lobo, World Journal of Surgery, Volume 33, Number 5, 931-937, DOI: 10.1007/s00268-009-9947-z.

[11] Alvarez AA, Maxwell GL, Rodriguez GC, Gynecol Oncol. 2001Mar;80(3):413-6.

[12] Howell M. Case study 000090-000307-000928 www.celleration.com 


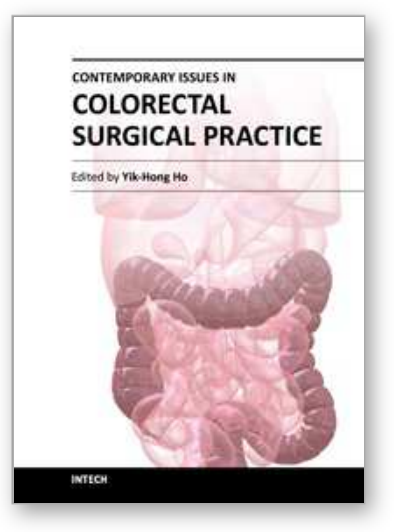

\author{
Contemporary Issues in Colorectal Surgical Practice \\ Edited by Dr. Yik- Hong Ho
}

ISBN 978-953-51-0257-1

Hard cover, 126 pages

Publisher InTech

Published online 16, March, 2012

Published in print edition March, 2012

In recent years, significant progress in colorectal surgery has been made which includes laparoscopic techniques, pre-operative management, emergency colorectal surgery, fast track multimodal recovery, management of complex wound problems and colorectal cancer follow-up. "Contemporary Issues in Colorectal Surgical Practice" aims to bridge the gap between the journal article and the traditional textbook in these areas.

\title{
How to reference
}

In order to correctly reference this scholarly work, feel free to copy and paste the following:

Prem Rathore (2012). Difficult Infected Wound After Colorectal Surgery, Contemporary Issues in Colorectal Surgical Practice, Dr. Yik- Hong Ho (Ed.), ISBN: 978-953-51-0257-1, InTech, Available from: http://www.intechopen.com/books/contemporary-issues-in-colorectal-surgical-practice/-difficult-infectedwound-after-colorectal-surgery-

\section{INTECH}

open science | open minds

\section{InTech Europe}

University Campus STeP Ri

Slavka Krautzeka 83/A

51000 Rijeka, Croatia

Phone: +385 (51) 770447

Fax: +385 (51) 686166

www.intechopen.com

\section{InTech China}

Unit 405, Office Block, Hotel Equatorial Shanghai

No.65, Yan An Road (West), Shanghai, 200040, China 中国上海市延安西路65号上海国际贵都大饭店办公楼 405 单元

Phone: +86-21-62489820

Fax: $+86-21-62489821$ 
(C) 2012 The Author(s). Licensee IntechOpen. This is an open access article distributed under the terms of the Creative Commons Attribution 3.0 License, which permits unrestricted use, distribution, and reproduction in any medium, provided the original work is properly cited. 